\title{
Multi-Scale Assessment of the Economic Impacts of Flooding: Evidence from Firm to Macro-Level Analysis in the Chinese Manufacturing Sector
}

\author{
Xi Hu ${ }^{1,2, *}$, Raghav Pant ${ }^{2}{ }^{-}$, Jim W. Hall ${ }^{2} \mathbb{D}$, Swenja Surminski ${ }^{3}$ and Jiashun Huang ${ }^{1,2,4}$ \\ 1 Labor and Worklife Program, Harvard Law School, Harvard University, Cambridge, MA 02138, USA; \\ jiashun.huang@sant.ox.ac.uk \\ 2 Environmental Change Institute, University of Oxford, Oxford OX1 3QY, UK; \\ raghav.pant@ouce.ox.ac.uk (R.P.); jim.hall@eci.ox.ac.uk (J.W.H.) \\ 3 Grantham Research Institute on Climate Change and the Environment, London School of Economics, \\ London WC2A 2AZ, UK; s.surminski@lse.ac.uk \\ 4 Institute for New Economic Thinking, Oxford Martin School, University of Oxford, Oxford OX2 6ED, UK \\ * Correspondence: xhu@law.harvard.edu; Tel.: +1-617-301-2199
}

Received: 28 December 2018; Accepted: 15 March 2019; Published: 1 April 2019

\begin{abstract}
We present an empirical study to systemically estimate flooding impacts, linking across scales from individual firms through to the macro levels in China. To this end, we combine a detailed firm-level econometric analysis of 399,356 firms with a macroeconomic input-output model to estimate flood impacts on China's manufacturing sector over the period 2003-2010. We find that large flooding events on average reduce firm outputs (measured by labor productivity) by about $28.3 \%$ per year. Using an input-output analysis, we estimate the potential macroeconomic impact to be a $12.3 \%$ annual loss in total output, which amounts to $15,416 \mathrm{RMB}$ billion. Impacts can propagate from manufacturing firms, which are the focus of our empirical analysis, through to other economic sectors that may not actually be located in floodplains but can still be affected by economic disruptions. Lagged flood effects over the following two years are estimated to be a further $5.4 \%$ at the firm level and their associated potential effects are at a 2.3\% loss in total output or 2,486 RMB billion at the macro-level. These results indicate that the scale of economic impacts from flooding is much larger than microanalyses of direct damage indicate, thus justifying greater action, at a policy level and by individual firms, to manage flood risk.
\end{abstract}

Keywords: natural disasters; flooding; indirect economic impact; manufacturing firms; China

\section{Introduction}

Flooding has a huge impact on the socio-economic well-being of nations. Between 2007 and 2016, 85 million people have been affected every year, and the associated economic losses amounted to US \$36.7 billion annually, according to the recent EM-DAT (the International Disaster Database) report [1]. While ample evidence exists at the macro-level, less has been written on firm-level impacts, which could be substantial. According to one Zurich Re sponsored survey of more than 550 global companies in 2011, 49\% reported lost productivity from adverse extreme events such as flooding, while their working costs increased by $38 \%$ and revenue decreased by $32 \%$ [2].

In this paper, we provide one of the first empirical studies that we are aware of that examines flooding impacts at the firm level across the whole of China, which became our geographical focus for several reasons. First, China is one of the hotspots of natural disasters in the world, especially prone to flooding impacts. Direct economic losses amounted to approximately US $\$ 32$ billion in $2017(0.26 \%$ of its GDP that year) [3]. Combined direct and indirect economic losses due to fluvial flooding in China 
are projected amongst the highest in the world in the next 20 years, with an increase of $82 \%$ [4]. Second, China is the world's manufacturing hub, producing over $90 \%$ of world's personal computers, $80 \%$ of world's air conditioners, and 70\% of world's mobile phones in 2014 [5]. Lesser known is the fact that most of these manufacturing sites are located in areas which are prone to flooding events of significant magnitude. Indeed, business losses are often reported in major media channels, yet little empirical evidence exists regarding the systematic firm-level impact over time.

Furthermore, flooding impacts at the firm level could propagate to the rest of the economy. For instance, the 2011 Thai floods, which inundated seven industrial parks in which 804 companies operated [6], provide the perfect demonstration of flooding impacts on the manufacturing sector and the aforementioned propagating effects to the rest of the economy. Due to the damage to these industrial parks, the sector contributed to an $8.6 \%$ decline of the real GDP between October and December 2011 in the country, and procurement was significantly lowered for many small firms $[6,7]$. Firms whose plants were not flooded-Toyota and Nissan-had their operations disrupted due to lack of parts from suppliers from other sectors which were located in flooded regions [6]. Also, $62 \%$ of non-manufacturing sectors such as finance, construction and civil engineering, and retail reported indirect losses due to supply chain/customers disruption [8], some of which would have been from the manufacturing sector due to the interrelationships between industries within the Thai economy. Furthermore, the world's industrial production decreased by $2.5 \%$, and many companies either imported parts from Japan or elsewhere in the Association of Southeast Asian Nations (ASEAN) region $[6,7]$.

The Chinese manufacturing sector is also particularly vulnerable to flooding, as many of the sites are located in flood-prone regions. Yet empirical evidence on firm-level impacts is virtually non-existent. This is not to postulate that there is no impact-every year, many listed companies report on revenue losses. In the 2016 floods, for example, Xinxiang Chemical Fiber Co lost US \$1.15 million, Hualan Biological Engineering lost many of its production facilities and TD Flow (Tongdu Liuti), a pipeline manufacturer halted production completely [9]. The consequences are severe to an extent that the concept of "flood protection stocks" developed, whereby investors purchases of stocks, whose businesses are involved in flood protection, surge during the flooding months every year across China. Beyond these reported losses in the media, we know very little about the impacts of non-listed firms. In the same year, the manufacturing purchasing managers' index fell to 49.9 in June, below the 50-point line delineating growth for the first time in four months, due to heavy rains and flooding in most of China's provinces, particularly those along the Yangtze River Basin, which had impacted production (down 0.4 percentage points to 52.1) and transportation, among other things [10]. Despite this, we know little about the potential wider macroeconomic impacts resulting from these disruptions at the firm level. As such, in this paper, we also aim to estimate the potential propagation of firm-level disruption effects to the rest of the Chinese economy.

The rest of the paper is outlined as follows. In Section 2 we present the relevant literature on flood impact at the firm and macro levels. Section 3 presents the data used in our case study, followed by an empirical analysis as well as information about how we estimate the wider macroeconomic impacts through an input-output model. In Section 4 we present the results of the analysis. Section 5 presents the conclusions and further steps for this study.

\section{Economic Impacts of Natural Disasters}

In the literature, the economic impacts of natural disasters have been the subject of extensive discussion [11-13]. The key aspects of discussions fall under different methods to categorize and estimate the costs [12,14]; establishing an empirical relationship between different natural disasters and macroeconomic performance indicators such as GDP and consumer prices, as well as the more recent use of nightlight satellite images that are proxies for economic development [15-18], and understanding the ways in which disasters affect the economy at varying levels spanning from the country to firms to individuals [19-21]. On the micro-level, many scholars have examined the impact 
of natural disasters on the property market, potentially lowering house values for those located in a floodplain [22,23]. In the case of China, it has been found, for example, that Chinese companies that face greater systemic risk, for example from natural disasters, tend to buy more property insurance than those with low systemic risks [24].

In general, however, less work has been written on the firm level. In the context of flooding, the majority of firm-level cost estimates come from post-event news reports, surveys or interviews, often in terms of reports of accidents, the production losses to firms resulting from particular floods, and the costs of repairing/replacing damaged property, business closure and/or insurance payouts for different sectors $[25,26]$. More systemic-albeit limited—empirical evidence has shown negative effects on firms from flooding, especially for those small businesses in the short term [27]. However, the relationship between flooding and firm performance is far from conclusive. On the one hand, Leiter et al., among others, find evidence that companies located in regions of floods could benefit from flooding [28-30]. One of the potential reasons is that, although natural disasters may physically affect the factors of production such as labor and capital, it is possible for firms to experience a higher growth of assets if lost capital is replaced and new technologies are adopted. On the other hand, if lost capital is not replaced, the level of production can be lowered permanently, therefore negatively impacting the firms' revenue streams. Indeed, small businesses have been shown to be particularly vulnerable, possibly due to the latter effect and because they have limited access to disaster loans among other mechanisms which would help them cope with flooding impacts [27]. Other factors such as company size, location, age, and ownership of firms may also affect firms' performance [27].

Firm-level impacts can also result in propagating effects on other parts of the economy. This is especially true in the manufacturing sector because manufacturing companies usually have complex supply chains and provide essential inputs to the production processes of other economic sectors. Take the example of the fabricated metal industry, which is a sub-sector of manufacturing which produces iron, steel, and various metals that are used in the construction industry for building roads and other types of transport infrastructure. The manufacturing sector also makes plumbing pipe parts which are essential for water supply infrastructure and providing boilers for electricity and heat production. If the manufacturing sector cannot produce due to a flood event, production in other sectors will also be affected, which would lead to further economic losses. Even if manufacturing firms are not flooded themselves, their operations may still be affected because they are located in flooded areas, which will then lead to propagating impacts on those sectors that rely on the manufacturing sector.

To estimate the propagating impacts of flooding, Computable General Equilibrium (CGE) and Input-Output (IO) based approaches have been applied [31,32]. CGE models capture propagating economic losses because they describe all price adjustments in the market in response to a shock [33]. Using the CGE model for quantifying the multi-regional macroeconomic impacts of flooding in Po River in Northern Italy, Carrera et al., highlight indirect losses from flooding in the national economic systems which are a significant share of the direct losses [33]. The IO-based models work on a somewhat different premise. The productive relationships between industries are estimated, capturing how each industry produces and consumes goods and services from others. The IO model and its variants have been used in similar ways to CGE models to make the case for indirect loss estimations of big disaster events at national and multi-regional scales [34-36]. Applying a hybrid input-output model, Koks et al., showed that the indirect losses in the Dutch economy from flooding events could be substantial for low-probability (big disaster) events [37]. Similarly, a multi-regional IO study showed substantial indirect economic losses across Europe due to flooding in Rotterdam [35]. Furthermore, IO analysis of the impacts of the 2011 earthquake and tsunami in Japan showed significant indirect losses to industries in China, Germany, South Korea, and the United States [36].

While there are extensive debates on the merits of CGE and IO models by themselves [38] and over each other [32,35], these model outcomes should be treated as one of many representations of a realistic post-disaster economy with the aim of highlighting overall economic influences between interconnected sectors [32]. In this paper, a simplified IO-based model [39] is employed to capture 
the potential propagation of supply-side disruptions to firm-level impacts to the macroeconomic level manufacturing sector, and further, to the rest of the Chinese economy. We note that the model used here employs a simplistic understanding of a disrupted macroeconomic IO system, and there are more advanced disaster-impact IO models that look at adaptive inventory management and post-disaster recovery behaviors $[34,37,40,41]$. The key difference here is that the purpose of our model is to capture the potential long-term averaged effects of the economy adjusting to supply-side losses in the manufacturing sector, whereas other more nuanced IO models are more focused on short-term post-disaster recovery $[34,37,40,41]$.

\section{Data and Methods}

Since the objective of our paper is to quantify the economic consequences of systemic disruptions to manufacturing firms due to large flooding events and the associated wider macroeconomic loss propagation effects, we present a data-driven framework that integrates econometric analysis with macroeconomic modeling. First, we estimate the effects of large-scale flooding events on firm performance across the manufacturing sector, using Chinese flooding data from 399,356 manufacturing companies between 2003 and 2010, which provides a reasonable representation of the manufacturing sector of China for the period of analysis considered here. To establish the empirical relationship between flooding and firm performance, we employed two-stage least square (2SLS) with an instrumental variable. Second, using economic input-output analysis, we estimate the potential propagation of firm-level disruption effects to the rest of a national economy.

\subsection{Data}

Our dataset on China's manufacturing sector covers a total of 399,356 individual companies with detailed information on firm revenues, employees, and addresses between 2003 and 2010, the summary statistics of which are in Table 1 [42]. It covers a range of manufacturing companies that vary in sizes, from those that employ as many as tens of thousands of workers, such as BYD Company, which is a Shenzhen-based car manufacturer employing 180,000 persons, to those very small companies that are run by a few business owners. It is also spread out across cities in China and includes companies from all manufacturing sectors from the national input and output tables, which means the sample should be representative of the overall manufacturing sector. The total number of sectors included is 23 (see Appendix A, Table A1).

Table 1. Variable summary statistics of the Chinese manufacturing firms.

\begin{tabular}{ccccc}
\hline Variable & Mean & $\begin{array}{c}\text { Standard } \\
\text { Deviation }\end{array}$ & $\begin{array}{c}\text { Minimum } \\
\text { (Thousand US Dollars) }\end{array}$ & $\begin{array}{c}\text { Maximum } \\
\text { (Thousand US Dollars) }\end{array}$ \\
\hline Revenue & $23,854.38$ & $219,296.2$ & 0.1280574 & $38,500,000$ \\
Employees & 269 & 1165 & 2 & 180,000 \\
\hline
\end{tabular}

Flooding data are collected from the Dartmouth Flood Observatory, which contains an archive of large floods in the world between 1985 and 2016 [43]. A record of 128 major floods in China is selected for the period between 2003 and 2010. The flood sample in this study consists of major reported flooding events in China. These are "derived from a wide variety of news and governmental sources", and are divided into three classes-large, very large, and extreme. Large flood events are defined as causing significant damage to structures or agriculture/fatalities; and/or with a decades-long reported interval since the last similar event. Very large events are those with a greater than 2-decade but less than 100-year estimated recurrence intervals, and / or a local recurrence interval of 1-2 decades and affecting a large geographic region ( $>5000 \mathrm{sq} . \mathrm{km})$. Extreme events have an estimated recurrence interval greater than 100 years. We use this sample of floods because these events are the most disruptive. Whilst smaller ones from other databases may inflict damage, they are less likely to have a 
production effect on manufacturing companies. The summary statistics of the flood variables from Dartmouth Observatory used are presented in Table 2.

Table 2. Variable descriptive statistics of the Dartmouth major reported floods in China between 1985-2016.

\begin{tabular}{cccccc}
\hline & $\begin{array}{c}\text { Duration } \\
\text { in Days }\end{array}$ & Dead & Displaced & Damage (USD) ${ }^{\mathbf{1}}$ & Affected sq. km \\
\hline Mean & 11 & 66 & 289,965 & 279 & $143,856.55$ \\
Standard Error & 1 & 14 & 63,131 & 76 & $23,299.46$ \\
Median & 6 & 17 & 37,700 & 37 & $46,140.00$ \\
Standard & 14 & 150 & 598,912 & 656 & $263,603.31$ \\
Deviation & 2 & 0 & 0 & - & 30.00 \\
Minimum & 81 & 1100 & $3,170,000$ & 4250 & $1,916,000.00$ \\
Maximum & 1427 & 7101 & $26,096,856$ & 206,601 & $18,413,639.00$ \\
Sum & 128 & 108 & 90 & 74.00 & 128.00 \\
Count & & 1 & & &
\end{tabular}

${ }^{1}$ Note: To the nearest million.

We georeferenced the company dataset to intersect with flooding records. Access to this spatial data provides us with the possibility of examining the spatial impact of flooding on Chinese firms for the first time. Figure 1 shows a zoomed-in map of the actual flooding extent between 1997 and 2010 in Guangdong province in China and the locations of manufacturing companies. Figure 2 depicts the locations of major flooding events between 2003 and 2010 and Chinese manufacturing firms. As we may observe, many cities where there are concentrations of manufacturing companies are exposed to floods.

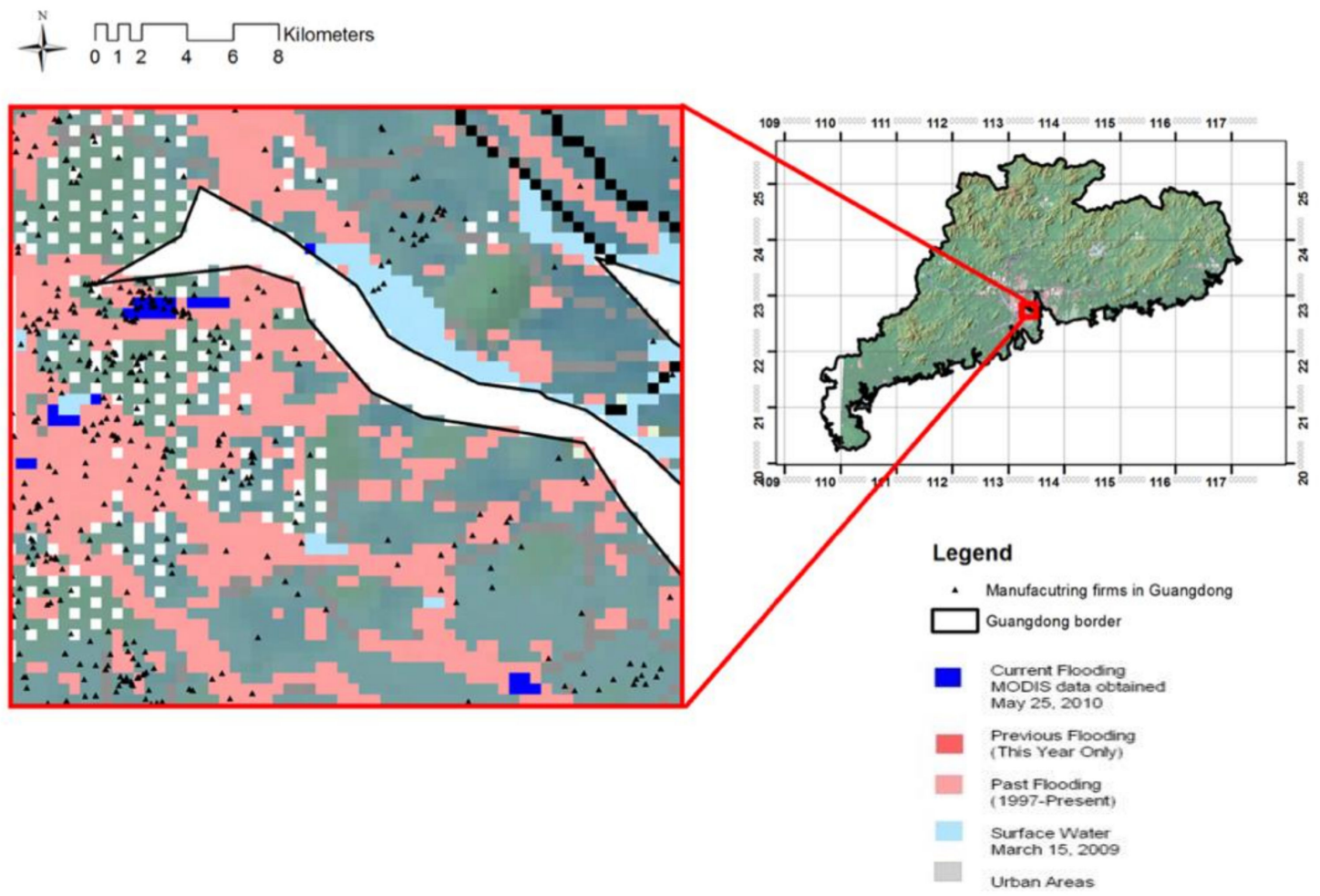

Figure 1. Locations of major reported flooding events in Guangzhou. Dark blue indicates the May mega flooding event in 2010; red indicates other flooding events in 2010; pink indicates flooding events between 1997 and 2010. Manufacturing companies are shown as black triangular dots. Blank areas indicate no data. Data source: Orbis and Dartmouth Flood Observatory 2016. 


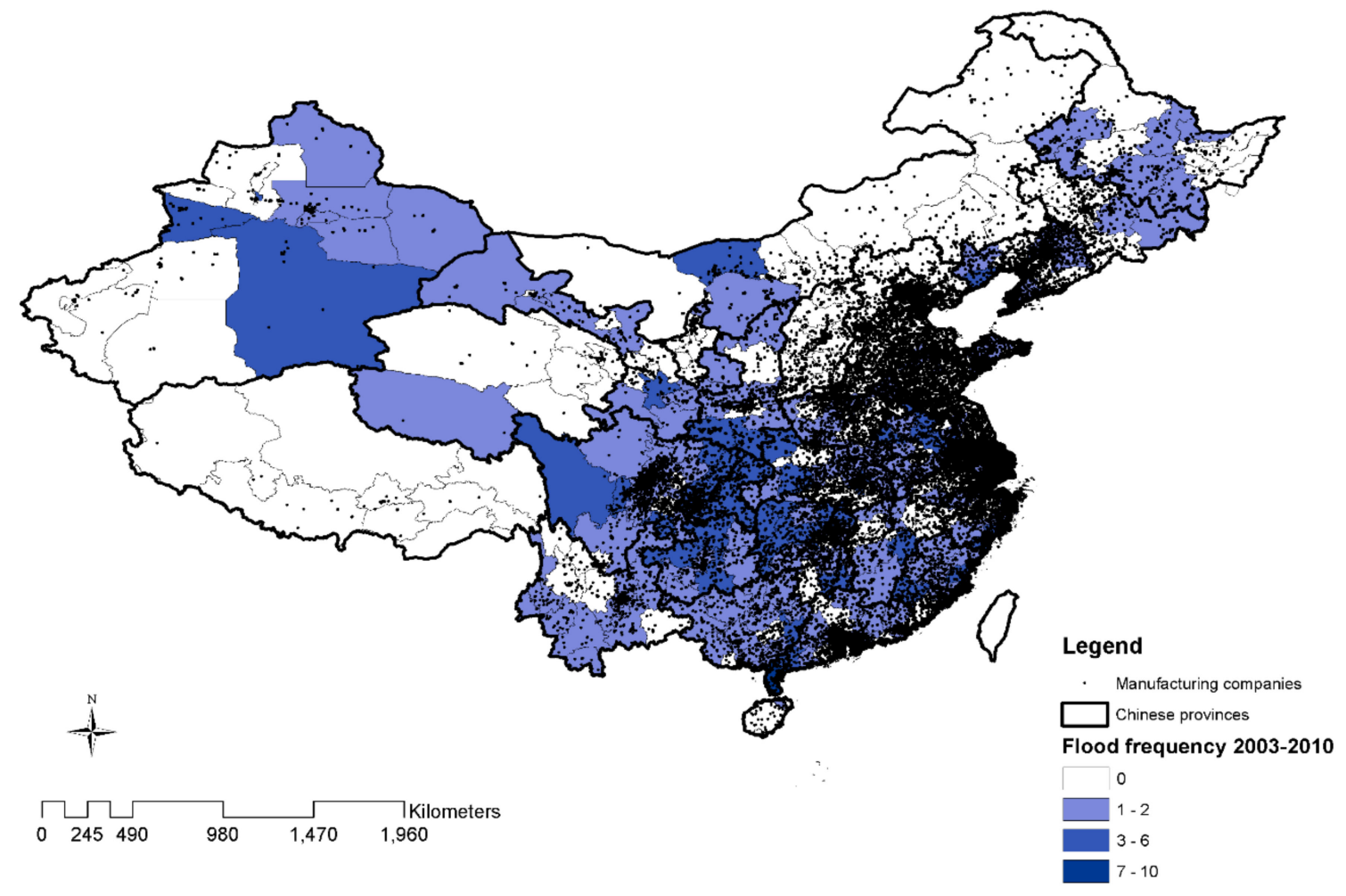

Figure 2. Locations of major reported flooding events at the city level between 2003 and 2010 and manufacturing companies in China. Data source: Dartmouth Flood Observatory (2016) and ORBIS (2017).

\subsection{Empirical Approach}

We conduct a regression analysis of Chinese flooding data and manufacturing companies in China from 2003-2010 to test the hypothesis that flooding has an effect, i.e., an impact on Chinese manufacturing companies, and estimate the magnitude of this effect. The structure of the regression model is as follows:

$$
y_{k t}=\beta_{F} F_{k t-1}+\alpha_{t}+\alpha_{k}+\varepsilon_{k t}
$$

where $k$ indexes firms, $t$ represents time, and $F_{k t-1}$ is a dummy variable that matches flooding at the firm level in the first year after flooding events. $\alpha_{t}$ and $\alpha_{k}$ are time-and-firm-fixed-effects respectively. $y_{k t}$ represents different firm-level outcomes, in this case, labor productivity. $\beta_{F}$ is the coefficient of the flood variable and $\varepsilon_{k t}$ are the errors in the regression.

In order to reduce the possibility of omitted variable bias, which occurs when important factors that affect the dependent variable are left out, we introduce fixed effects that (1) vary across firms but not over time (here defined as firm-fixed effects effects) and/or (2) vary over time but not across firms (time-fixed effects) [44]. In this specific study, one firm-fixed effect could be the competence of management, which is unlikely to vary much over an 8-year period. The management tenure length, which is completely unobserved in the error term, may affect labor productivity (defined as the revenue/number of employees) and the response variable directly by influencing the number of employees. A time-fixed effect in this study could be a health and safety regulation that influences the productivity of the firm but does not change over the 8-year period. Controlling for such effects will reduce the standard errors of the regression, thus increasing the precision of the measure in question. By this means internal validity can be attained, meaning the statistical inferences about the causal effects of flooding on productivity are valid for the companies studied. To ensure that the fixed effect model was the more suitable approach to the random effect model, we perform a Hausman test (see 
Appendix B). The results of the test Prob $>$ chi2 is less than 0.05 , which indicates a fixed effect model is preferred and thus justifies our model choice.

Although fixed-effects help to deal with problems of omitted variable bias, other sources of endogeneity of reverse causality and measurement errors can still be present. To address these concerns, one solution is employing the two-stage least square approach and introducing an instrumental variable, which in our case is defined as the average of flooding frequency per year in the neighboring cities $Z_{f}$. Formally, it is written as:

$$
\mathrm{Z}_{f}=\frac{\sum F_{n}}{\mathrm{C}}
$$

where $F_{n}$ is the flood frequency in neighboring cities and $C$ is the number of neighboring cities.

The instrumental variable introduced here meets two of the main requirements. Firstly, there is a strong correlation between the flood events in the city that the company is located in and its neighbors experiencing the same events. Often, a large flood, such as the ones in our database, would affect one or two neighboring cities at the same time. Second, the floods in neighboring cities do not correlate with the error terms and do not directly determine firms' labor productivity.

\subsubsection{Labor Productivity}

Based on Haltiwanger et al., (1999), labor productivity $y_{k t}$ is taken as:

$$
y_{k t}=\frac{R}{E}
$$

where $R$ is the total revenue of a company in a year and $E$ is the number of employees [45].

It is an efficiency measure based on how much output each worker can produce. This is a good proxy for measuring a company's outcome because the more efficient a company is, the more output for each employee, the better the performance. Usually, value added per employee is regarded as superior to revenue as a measure of output because it excludes the value of immediate inputs such as materials that are not produced by the companies, thus reflecting the marginal values that firms are creating. However, data for calculating value added were not available; therefore, revenue per year is used instead. In practice, revenue can be reduced when there is the cost of moving out or moving back in after a flooding event, or the cost of lost merchandise or goods.

\subsubsection{Estimation}

We use three model specifications based on Equation (1). Fixed effects regressions are then run according to the different model specifications.

Model 1: This model focuses on firm-fixed and year-fixed effects. The null and alternative hypotheses are stated below.

$H_{1}$ (null): Flooding has no effect on Chinese manufacturing companies' productivity, (controlling for firm-and year-fixed effects).

$H_{1}$ (alternative): Flooding has an effect on Chinese manufacturing companies' productivity, (controlling for firm-and year-fixed effects).

Model 2: This model focuses on firm-fixed and sector-year-fixed-effects. These could be regulations that do not change over time for one sector, e.g., chemical controls, whereas they do change for another, e.g., mining. This is a more robust model than the first because introducing specific sector-year effects controls for more "fixed effects", whereas Model 1 only includes fixed effects that do not change over time for all companies. The null and alternative hypotheses are stated below.

$\mathrm{H}_{2}$ (null): Flooding has no effect on Chinese manufacturing companies' productivity, controlling for firm-and sector-year-fixed-effects.

$\mathrm{H}_{2}$ (alternative): Flooding has an effect on Chinese manufacturing companies' productivity, controlling for firm-and sector-year-fixed-effects. 
Model 3: This model examines the possibility of a lagged effect of flooding, with firm-fixed and sector-year-fixed effects. The null and alternative hypotheses are stated below.

$\mathrm{H}_{3}$ (null): Flooding has no lagged effect (two-year shock specified) on Chinese manufacturing companies' productivity, controlling for firm-and sector-year-fixed-effects.

$\mathrm{H}_{3}$ (alternative): Flooding has a lagged effect (two-year shock specified) on Chinese manufacturing companies' productivity, controlling for firm-and sector-year-fixed-effects.

In addition, all three models are run on a log-linear transformation on labor productivity. This will make the interpretation easier, i.e., in percentage terms, if flooding is significant. We eliminate those observations that have their labor productivity as zero since the logarithm of zero is undefined. The equation is:

$$
\log \left(y_{k t}\right)=\theta_{f} Z_{f t-1}+\gamma_{t}+\gamma_{i}+v_{k t}
$$

where $Z_{f t-1}$ is the instrumental variable from Equation (2) replacing the flooding dummy variable $F_{k t-1}$ in Equation (1).

All hypotheses are tested at a 1, 5 and $10 \%$ level of significance.

\subsection{Input-Output Analysis}

From the econometric models, we obtain the estimated expected annual firm-level labor productivity losses to subsequently estimate the expected annual macroeconomic losses due to flooding.

The sectors involved in manufacturing are part of a much larger economy, which is assumed to be comprised of $n$ interacting sectors, of which an example sector $i$ is a part. This economy has a supply and demand balance where sectors (through firms) supply goods and services to satisfy the demands of other sectors, households, and the government, and in return use resources from other sectors, households and the government to produce more. This balance is represented by the input-output Equation (5), where the total economic output of sector $i$, given by $x_{i}$, goes as input towards satisfying the intermediate demands, $z_{i j}, j=\{1, \ldots n\}$, of different sectors and the final demands, $f_{i}$, of households and government.

$$
x_{i}=\sum_{j=1}^{n} z_{i j}+f_{i}
$$

It is further assumed that the value of intermediate sector demand of sector $i$ output by a sector $j$, $z_{i j}$, is proportional to the total sector $j$ output $x_{j}$. This relationship, expressed in Equation (6), is derived from the cost minimization under a Walras-Leontief production function [46]. Here $a_{i j}$ is a technical coefficient whose value lies between 0 and 1 .

$$
z_{i j}=a_{i j} x_{j}
$$

Substituting Equation (6) into Equation (5) produces the Leontief economic input-output model [47] of Equation (7) for the supply-demand equilibrium balance of the economy.

$$
x_{i}=\sum_{j=1}^{n} a_{i j} x_{j}+f_{i} \Longleftrightarrow \mathbf{x}=\mathbf{A x}+\mathbf{f}
$$

Here, $\mathbf{x}$ is the $n \times 1$ vector of sector outputs, A the $n \times n$ matrix of technical coefficients matrix, and is $\mathbf{f}$ the $n \times 1$ vector of exogenous demands.

The Leontief input-output model of Equation (7) is a model of an open demand-driven economy because of the exogenous demand vector $f$. To estimate direct and indirect macroeconomic flow losses through this model we need demand-side perturbation effects. But in the case of a disaster such as flooding, supply-side perturbation effects, such as productivity losses, generally result in direct and 
indirect economic losses [34]. To represent supply side perturbations we convert the open economy Leontief input-output model into a closed economy Leontief input-output model [39]. An additional labor constraint given by Equation (8) is introduced, where the $L$ is a scalar of total employment, 1 is an $n \times 1$ vector of direct labor input coefficients, and $\mathbf{l}^{\prime}$ is the transpose of $\mathbf{l}$.

$$
L=\sum_{j=1}^{n} l_{j} x_{j} \Longleftrightarrow L=\mathbf{1}^{\prime} \mathbf{x}
$$

Combining Equations (7) and (8) and rearranging them produces the 'Basic-Equation' [39], which describes a closed Leontief input-output economic model of a balanced economy. This is shown in Equation (10), which follows from Equation (9).

$$
\left[\begin{array}{cc}
\mathbf{A} & \mathbf{f} / L \\
\mathbf{1}^{\prime} & 0
\end{array}\right]\left[\begin{array}{l}
\mathbf{x} \\
L
\end{array}\right]=\left[\begin{array}{l}
\mathbf{x} \\
L
\end{array}\right]
$$

Or

$$
\begin{aligned}
& \mathbf{M q}=\mathbf{q} \\
& \text { Where } \mathbf{M}=\left[\begin{array}{cc}
\mathbf{A} & \mathbf{f} / L \\
\mathbf{l}^{\prime} & 0
\end{array}\right] \text { and } \mathbf{q}=\left[\begin{array}{l}
\mathbf{x} \\
L
\end{array}\right]
\end{aligned}
$$

In Equation (10) the left side, Mq, represents the totality of inputs and the right side, $\mathbf{q}$, represents the totality of outputs [39]. The equilibrium condition $\mathbf{M q}=\mathbf{q}$ shows the ability of the economy to produce if the sector capacities are at levels $\mathbf{q}[39]$.

Due to a flood disruption, we assume the production capacity of the firms is decreased, which reduces the production capacity of the economic sector. We assume the production capacity of the sector $i$ is lost by a fraction $0 \leq \delta_{i} \leq 1$. Similarly, the production capacity of labor is lost by $0 \leq \delta_{n+1} \leq 1$. We can construct a vector, $\tilde{\mathbf{q}}$, of the remaining post-disaster production capacity as:

$$
\tilde{\mathbf{q}}=\left[\begin{array}{ccc}
1-\delta_{1} & \cdots & 0 \\
\vdots & \ddots & \vdots \\
0 & \cdots & 1-\delta_{n+1}
\end{array}\right] \mathbf{q}=[\mathbf{I}-\mathbf{D}] \mathbf{q}
$$

where $\mathbf{I}$ is the $(n+1) \times(n+1)$ identity matrix, and $\mathbf{D}=\operatorname{diag}\left(\delta_{i}\right), \forall i=\{1, \ldots, n+1\}$.

Because of the reduced production capacities, the post-disaster economy will become imbalanced and produce a reduced output given by:

$$
\hat{\mathbf{q}}^{0}=\mathbf{M} \tilde{\mathbf{q}} \neq \tilde{\mathbf{q}}
$$

$\hat{\mathbf{q}}^{0}=\left[\begin{array}{cc}\hat{\mathbf{x}}^{0} & \hat{L}^{0}\end{array}\right]^{\prime}$ where $\hat{\mathbf{x}}^{0}$ is the vector-reduced economic outputs of all sectors and $\hat{L}^{0}$ is the reduced total labor wages in the economy after the disaster event. Equation (12) represents the post-disruption economic outputs of an imbalanced economy, which can be treated as estimates of the initial inability of the total outputs to meet the total demands in the economy [37,39]. Subsequently, the economy would have to readjust its circular flows to ultimately attain other equilibrium levels. We assume that the new equilibrium state is reached by readjusting final demands and total employment levels, corresponding to the reduced output levels $\hat{\mathbf{x}}^{0}$. This assumption is consistent with the notion that in post-disaster situations firms will prioritize intermediate demands for other sectors over final demands $[40,41]$. Hence the new balanced economy is estimated by solving the Equation (13) system of equations. We note that the value of $\hat{L}$ estimated from Equation (13) replaces the value estimated from Equation (12).

$$
\hat{\mathbf{x}}=\hat{\mathbf{x}} ; \hat{\mathbf{f}}=\hat{\mathbf{x}}^{1}-\mathbf{A} \hat{\mathbf{x}}^{1} ; \hat{L}^{1}=\mathbf{l}^{\prime \hat{x}^{1}}
$$


From Equations (10) and (13), we can estimate the losses in economic outputs, $\Delta \mathbf{x}=\mathbf{x}-\hat{\mathbf{x}}$, final demands $\Delta \mathbf{f}=\mathbf{f}-\hat{\mathbf{f}}$, and labor wages $\Delta L=L-\hat{L}^{1}$.

In considering flood-lagged firm-level disruption effects, it is assumed that these lagged disruptions are realized after the economy is in equilibrium following the first stage of disruptions. Hence, they represent a second shock on the economy whose Basic-equitation presentation of Equation (10) has outputs $\hat{\mathbf{x}}^{1}$, final demands $\hat{\mathbf{f}}$, and total employment $\hat{L}^{1}$. Subsequently, the new equilibrium and economic losses from these disruptions are estimated by repeating the steps from Equation (11) to Equation (13).

The macroeconomic losses depend upon estimating the matrix $\mathbf{D}$, which is estimated from firm-level labor productivity losses of the econometric models for Equation (4). The coefficient $\theta_{f}$ represents the average fractional loss of labor productivity, which we use as a measure of loss of production capacity. For all firms belonging to a sector $i$ we get

$$
\delta_{i}=\left(\theta_{f}\right)_{i}
$$

The loss of production capacity of labor occurs due to labor deaths, which are not considered here. This means in our model $\delta_{n+1}=0$.

Since the econometric models give us robust estimates of $\theta_{f}$ with mean and standard error estimates, we can estimate the direct and indirect flow losses over a range of possible values to show the uncertainties in these values.

\section{Results}

\subsection{Empirical Analysis}

After employing the 2SLS by introducing an instrumental variable $\mathrm{Z}_{f t-1}$, the results for flooding impact on the logarithm of labor productivity are presented in Table 3. All three regression models, including Model 1, Model 2, and Model 3 ubiquitously show a negative impact-significant at the 1\% level for Model 1 and Model 2, and the 5\% level for Model 3. Since Model 2 is more robust compared with Model 1, we employ and interpret the results from Model 2 as flooding reduces the output of Chinese manufacturing companies by $28.3 \%$ on average in the year after flooding occurs. Interestingly, the lagged flooding effect, from Model 3 is also significant at the $5 \%$ level, standing at -0.0540 . We can interpret this as an average reduction of output by $5.4 \%$ as a result of lagged flooding impacts on the Chinese manufacturing sector in the two years after flooding occurs.

Table 3. Estimated results of fixed-effects models using the instrumental variable $Z_{f t-1}$.

\begin{tabular}{cccc}
\hline \multirow{2}{*}{ Variables } & Model (1) & Model (2) & Model (3) \\
\cline { 2 - 4 } & Log Productivity & Log Productivity & Log Productivity \\
\hline \multirow{2}{*}{ Flood } & $-0.655^{* * *}$ & $-0.283^{* * *}$ & - \\
& $(0.0143)$ & $(0.0152)$ & $-0.0540^{* *}$ \\
Flood_lagged & - & - & $(0.0181)$ \\
Sector Control & - & Yes & Yes \\
Year & Yes & Yes & Yes \\
N & 431,538 & 431,538 & 272,402 \\
\hline
\end{tabular}

Notes: These regressions were estimated using panel data for major flooding events in China on 399,356 Chinese manufacturing companies between 2003 and 2010. Model (1) focuses on firm-fixed and year-fixed-effects; Model (2) focuses on firm-fixed and sector-year-fixed-effects; Model (3) examines the possibility of a two-year lagged effect of flooding. Standard errors in parentheses. ${ }^{* *} p<0.01,{ }^{* *} p<0.05,{ }^{*} p<0.1$. 


\subsection{Macroeconomic Analysis}

For the macroeconomic analysis, we have taken the $2010 \mathrm{IO}$ accounts of the Chinese economy. In these IO accounts the Chinese economy is disaggregated into 41 sectors, from which we are able to build the Basic Equation model Equation (10). Sixteen sectors, from numbers 6-21, are the manufacturing-based sectors to which our 399,356 companies belong. We assume that these 399,356 companies exhaustively make up the whole of the manufacturing sector.

Given the results of the Model 1 are less robust due to the omission of sector-year fixed effects, we present macroeconomic analysis results only for the more robust Model 2 and Model 3 results. As the econometric analysis of Model 2 shows, all manufacturing-based firms suffer an average labor productivity loss of $\bar{\theta}_{f}=0.283$ due to flooding. This for us implies that the firm capacities and correspondingly the production capacity of all manufacturing-based sectors declines by $28.3 \%$, i.e., $\delta_{i}=0.283, \forall i=\{6, \ldots, 21\}$. We assume all sectors which are not manufacturing-based do not suffer any capacity reductions, i.e., $\delta_{i}=0, \forall i \neq\{6, \ldots, 21\}$.

With the above assumptions, we are able to construct the $\mathbf{D}$ matrix and obtain the reduced post-disaster production capacities $\tilde{\mathbf{q}}$ from Equation (11). This allows us to find the new economic equilibrium, which gives the reduced economic outputs $\left(\hat{\mathbf{x}}^{1}\right)$, exogenous demands $(\hat{\mathbf{f}})$, and labor wages $\left(\hat{L}^{1}\right)$ from Equations (12) and (13). Subsequently, we can find the loss of outputs, demands and labor wages. These losses are reported as the annual losses for the Model 2 estimates of labor productivity losses. These losses are estimated for the average and the standard error ranges at $1 \%$ and $99 \%$ confidence intervals of $\theta_{f}$ estimates.

For Model 3 we have flood-lagged effects due to which there are further macroeconomic losses over the next two years. Assuming the same 2010 IO structure, we take the new Model 2 equilibrium at the end of year two and repeat the whole process above with $\delta_{i}=0.054, \forall i=\{6, \ldots, 21\}$ corresponding a $\bar{\theta}_{f}=5.4 \%$ decline in labor productivity due to flood lagged effects. Again, the losses are estimates for the average, and the standard error ranges are at $5 \%$ and $95 \%$ confidence intervals of values.

Table 4 shows the percentages and total losses in macroeconomic sector outputs, exogenous demands, and total labor wages for Model 2 for the initial impact, Model 3 for the lagged impact, and their summed (cumulative) estimates for impacts over the two years. The two models show potential substantial losses for the Chinese economy, highlighting the importance of the manufacturing sectors. We see that overall, due to $28.3 \%$ mean reductions in initial labor productivity of the sectors involved in manufacturing, the Chinese economy could suffer $12.31 \%$ mean losses in total direct and indirect economic flow losses, which amounts to 15,416 RMB billion. Since economic outputs are reduced, there is an effect on the total labor wages, which suffer mean losses of $10.44 \%$ or 1944 RMB billion. As a result, the overall demand for sector outputs could also reduce, which is seen in terms of mean losses of demand of $11.08 \%$ or 4471 RMB billion. Further lagged losses, resulting in cumulative losses over the next year, amount to $2.26 \%$ or 2486 RMB billion mean total sector output losses over the next year. Over the two years, mean values of $14.57 \%$ or $17,903 \mathrm{RMB}$ billion of macroeconomic output losses, $13.09 \%$ or 5194 RMB billion of exogenous demand losses, and $12.35 \%$ or 2321 RMB billion of labor wage losses are recorded. These estimated values show the profound influence of manufacturing-firm-level disruptions on the overall economy. The standard errors also show the large uncertainties in these estimates.

Through the IO analysis, we can break down the economic losses into sector-specific estimates. These provide more clarity in breaking down the direct and indirect macroeconomic flow loss impacts on the economy. Table 5 shows the values of sector output losses $\Delta \mathbf{x}=\mathbf{x}-\hat{\mathbf{x}}$ along with the standard error estimates, in terms of magnitudes in RMB billions. The manufacturing and non-manufacturing sectors have been separately highlighted to show that the IO loss effects cascade beyond manufacturing sectors to the rest of the economy. While the results for the manufacturing sector show the combined direct and indirect flow losses, for all other sectors these are purely indirect flow losses. We observe that industries involving as metal smelting and rolling processing and chemicals suffer the highest 
losses at 1969 and 1967 RMB billion, respectively. There are also substantial economic output losses incurred by the non-manufacturing sectors such as agriculture, forestry, animal husbandry, and fishery (1127 RMB billions), oil and gas exploration (536 RMB billions), and key infrastructure sectors such as electricity, heat production, and supply (518 RMB billions) and transportation and warehousing (483 RMB billions). Overall, service industries tend to be less affected. In addition, the lagged losses for the second year are still significant in the manufacturing-based sectors like metal smelting, rolling processing, (312 RMB billions) chemicals, (307 RMB billions) and others. This then further propagates towards the non-manufacturing sectors-agriculture, forestry, animal husbandry and fishery (191 RMB billions), oil and gas exploration (87 RMB billions), metal mining (69 RMB billions), electricity, heat production and supply (81 RMB billions), transportation and warehousing (78 RMB billions), and the wholesale and retail trade (68 RMB billions) industries.

Table 4. Results for the overall annual IO macroeconomic losses for the 2010 Chinese 41-sector economy.

\begin{tabular}{llll}
\hline & Model (2) & Model (3) & Cumulative \\
\hline \% Losses & & & \\
\hline Total Sector Output & $12.31(0.66)$ & $2.26(0.79)$ & $14.57(1.45)$ \\
$\quad$ Total Exogenous & $11.08(0.59)$ & $2.02(0.71)$ & $13.09(1.30)$ \\
$\quad$ Demands & $10.44(0.56)$ & $1.91(0.67)$ & $12.35(1.23)$ \\
Total Labor Wages & & & \\
\hline Loss Values (RMB billions) & & $2486(977)$ & $17,903(1805)$ \\
\hline Total Sector Output & $15,416(828)$ & $723(283)$ & $5194(523)$ \\
$\quad$ Total Exogenous & $4471(240)$ & $326(126)$ & $2321(233)$ \\
$\quad$ Demands & $1994(107)$ & &
\end{tabular}

Note: The results are shown as percentages and magnitudes of losses in total sector outputs, exogenous demands and total labor wages. Standard error values are in brackets.

In Table 5, the sector-specific percentage output losses for two years are shown. We observe that in terms of percentages, the losses are more severe for the indirectly affected sectors, with oil and gas exploration and metals mining sectors suffering the highest losses of $45.94 \%$ and $41.91 \%$, respectively. The lagged percentage losses after a year of flooding events are then subsequently also higher for these sectors, with oil and gas showing $13.8 \%$ loss of outputs, and metal mining showing $10.52 \%$ losses of outputs. The main drivers of these indirect effects are due to the strong input-output linkages of the oil and gas exploration sector with the chemicals sector ( $21.1 \%$ output loss in year one and $4.19 \%$ output loss in year two), and the metals mining sector with the metal smelting and rolling processing sector (24\% output loss in year 1 and $5 \%$ output loss in year two). These two sectors record the highest percentage outputs losses amongst all manufacturing sectors.

Comparatively, the percentages and absolute values in Table 5 also highlight the differences in the indirect losses when assessed in absolute terms and percentages respectively. In particular, we see that in terms of absolute magnitudes, the manufacturing-based sectors incur the highest losses, which is as expected. But in percentage terms, the indirect macroeconomic flow losses are relatively more severe for non-manufacturing sectors. This distinction could be crucial in disaster recovery planning. 
Table 5. Model 2 and 3 results showing the sector-specific mean and standard error percentage and total output losses for 2 years for the 41-sector Chinese economy.

\begin{tabular}{|c|c|c|c|c|c|}
\hline NO & Sector & $\begin{array}{l}\text { Output Loss } \\
\text { Model } 2 \text { (\%) }\end{array}$ & $\begin{array}{l}\text { Output Loss } \\
\text { Model } 3(\%)\end{array}$ & $\begin{array}{c}\text { Output Loss } \\
\text { Model } 2 \text { (RMB bn) }\end{array}$ & $\begin{array}{c}\text { Output Loss } \\
\text { Model } 3 \text { (RMB bn) }\end{array}$ \\
\hline 1 & Agriculture, forestry, animal husbandry and fishery & $16.27(0.87)$ & $3.29(1.04)$ & $1127(60)$ & $191(71)$ \\
\hline 2 & Coal mining and washing & $14.15(0.76)$ & $2.62(0.9)$ & $285(15)$ & $45(18)$ \\
\hline 3 & Oil and gas exploration industry & $45.94(2.47)$ & $13.8(2.99)$ & $536(28)$ & $87(34)$ \\
\hline 4 & Metal mining industry & $41.91(2.25)$ & $10.52(2.71)$ & $478(25)$ & $69(30)$ \\
\hline 5 & And other non-metallic mineral mining industry & $22.12(1.19)$ & $4.61(1.42)$ & $119(6)$ & $19(7)$ \\
\hline 6 & Food manufacturing and tobacco processing industry & $7.81(0.42)$ & $1.46(0.5)$ & $526(28)$ & $90(33)$ \\
\hline 7 & Textile Industry & $19.97(1.07)$ & $4.03(1.28)$ & $651(34)$ & $105(41)$ \\
\hline 8 & Textile, leather and feather products industry & $7.64(0.41)$ & $1.4(0.49)$ & $184(9)$ & $31(11)$ \\
\hline 9 & Wood processing and furniture manufacturing & $13.87(0.75)$ & $2.64(0.89)$ & 208 (11) & $34(13)$ \\
\hline 10 & Paper printing and Educational and Sports Goods & $16.67(0.9)$ & $3.24(1.07)$ & $346(18)$ & $56(21)$ \\
\hline 11 & Petroleum processing, coking and nuclear fuel processing industry & $14.14(0.76)$ & $2.56(0.9)$ & $426(22)$ & $66(26)$ \\
\hline 12 & chemical industry & $21.1(1.13)$ & $4.19(1.35)$ & 1967 (105) & 307 (124) \\
\hline 13 & Non-metallic mineral products industry & $10.42(0.56)$ & $1.92(0.67)$ & $417(22)$ & $68(26)$ \\
\hline 14 & Metal smelting and rolling processing industry & $23.99(1.29)$ & $5.0(1.54)$ & 1969 (105) & $312(124)$ \\
\hline 15 & Fabricated Metal Products & $17.39(0.93)$ & $3.42(1.11)$ & $425(22)$ & $69(27)$ \\
\hline 16 & $\mathrm{GM}$, special equipment manufacturing industry & $13.43(0.72)$ & $2.54(0.86)$ & $890(47)$ & $145(56)$ \\
\hline 17 & Transportation Equipment Manufacturing & $11.0(0.59)$ & $2.08(0.7)$ & $645(34)$ & $108(41)$ \\
\hline 18 & Electrical machinery and equipment manufacturing & $9.99(0.54)$ & $1.85(0.64)$ & $458(24)$ & $76(29)$ \\
\hline 19 & Communications equipment, computers and other electronic equipment manufacturing & $17.1(0.92)$ & $3.29(1.09)$ & $967(51)$ & $154(61)$ \\
\hline 20 & Instruments and cultural office machinery manufacturing & $17.59(0.94)$ & $3.42(1.13)$ & $125(6)$ & $20(7)$ \\
\hline 21 & Crafts and other manufacturing industries (including scrap waste) & $20.46(1.1)$ & $4.03(1.31)$ & 279 (15) & $43(17)$ \\
\hline 22 & Electricity, heat production and supply industry & $11.85(0.64)$ & $2.12(0.76)$ & $518(27)$ & $81(32)$ \\
\hline 23 & Gas Production and Supply & $9.16(0.49)$ & $1.59(0.58)$ & $20(1)$ & $3(1)$ \\
\hline 24 & Water production and supply industry & $7.05(0.38)$ & $1.21(0.45)$ & $12(0)$ & $1(0)$ \\
\hline 25 & Building industry & $0.06(0.0)$ & $0.01(0.0)$ & $5(0)$ & $0(0)$ \\
\hline 26 & Transportation and warehousing & $10.07(0.54)$ & $1.82(0.64)$ & $483(25)$ & $78(30)$ \\
\hline 27 & Postal services & $7.33(0.39)$ & $1.28(0.47)$ & $9(0)$ & $1(0)$ \\
\hline 28 & Information transmission, computer services and software industry & $4.38(0.24)$ & $0.72(0.28)$ & $73(3)$ & $11(4)$ \\
\hline 29 & Wholesale and retail trade & $9.82(0.53)$ & $1.77(0.63)$ & $422(22)$ & $68(26)$ \\
\hline 30 & Accommodation and catering industry & $5.0(0.27)$ & $0.85(0.32)$ & $108(5)$ & $17(6)$ \\
\hline 31 & Financial Industry & $8.33(0.45)$ & $1.46(0.53)$ & $268(14)$ & $43(17)$ \\
\hline 32 & Real Estate & $1.51(0.08)$ & $0.25(0.1)$ & $45(2)$ & $7(2)$ \\
\hline 33 & Leasing and Business Services & $9.22(0.5)$ & $1.67(0.59)$ & $200(10)$ & $33(12)$ \\
\hline 34 & Research and experimental development industry & $15.19(0.82)$ & $2.9(0.97)$ & $47(2)$ & $7(3)$ \\
\hline 35 & Integrated Technology Services & $9.27(0.5)$ & $1.65(0.59)$ & $82(4)$ & $13(5)$ \\
\hline 36 & Water conservancy, environment and public facilities management industry & $1.91(0.1)$ & $0.31(0.12)$ & $8(0)$ & $1(0)$ \\
\hline 37 & Resident Services and Other Services & $2.27(0.12)$ & $0.37(0.14)$ & $27(1)$ & $4(1)$ \\
\hline 38 & Education & $0.16(0.01)$ & $0.03(0.01)$ & $2(0)$ & $0(0)$ \\
\hline 39 & Health, social security and social welfare & $1.22(0.07)$ & $0.2(0.08)$ & $20(1)$ & $3(1)$ \\
\hline 40 & Culture, Sports and Entertainment & $3.91(0.21)$ & $0.66(0.25)$ & $19(1)$ & $3(1)$ \\
\hline 41 & Public administration and social organizations & $0.09(0.0)$ & $0.01(0.01)$ & $2(0)$ & $0(0)$ \\
\hline
\end{tabular}

Note: The manufacturing-based sector are highlighted in grey to show which sectors are directly impacted by labor productivity losses. All other sectors are indirectly affected due to the IO linkages with the manufacturing-based sectors. 


\section{Discussion}

We have combined detailed firm-level econometric analysis with a macroeconomic input-output model to provide a data-driven approach. From the econometric analysis of manufacturing-based firms in China, we found that flooding on average reduces manufacturing firm output by $28.3 \%$ per year. Assuming these firm-level output reductions are systemic across the manufacturing sector, we quantify their propagating effects on the Chinese macroeconomic system via a supply-side driven IO impact assessment model. In 2010, the annual direct losses as documented by the Chinese Ministry of Water Resources were estimated at 374 RMB billion (At 2010 prices) [48]. Our analysis shows that there is a $12.3 \%$ mean annual propagating loss in total direct and indirect macroeconomic flows, which could amount to 15,416 RMB billions. We also consider flood lagged effects over the two years and find that there could be a further 5\% at the firm level and $2.3 \%$ or 2486 RMB billion of mean total direct and indirect macroeconomic flow losses in the Chinese economy at the macro-level. Estimates for losses in labor wages and final demands are also reported.

In terms of economic sectors, we observe that within the whole Chinese manufacturing sector, industries such as chemical and metal smelting and rolling processing industries could suffer the highest losses at 1969 and 1967 billion, respectively. As for the non-manufacturing sectors, we observe significant impacts on agriculture, oil and gas, metal mining, and key infrastructure sectors such as the electricity, heat production and supply industry, gas production and supply, the water production and supply industry, the building industry, the transportation and warehousing industry, the information transmission, and computer services and software industry. Magnitude-wise, we see that agriculture, oil and gas, electricity, and transport sectors could incur more severe losses than several manufacturing sectors.

In absolute percentages, we observe that indirect macroeconomic flow losses are more widespread across the economy than the direct impacts with the oil and gas and mining sectors incurring greater percentage losses than manufacturing sectors. Such results highlight the interconnected nature of the economy and the importance of the manufacturing sectors to the outputs of other sectors.

Further significant lagged losses are observed for the whole economic system. As such, we demonstrate how the interdependency of different sectors could result in losses from one sector to the next and provide evidence as to which sector might be affected the most. Thus, an important implication of our work is that simply being located in areas where there have been large floods could have a significant cost for firms, not only those in the affected regions, but also much more broadly. It is crucial for us to study how sectors and ultimately firms are related, for instance, the supply chain and the spatial interrelationships of sectors and firms. This has not only implications across sectors within China, but also internationally through trade relationships and supply chains. The need to better understand these interconnected risks for businesses across the world was, for example, highlighted by the UK Climate Change Risk Assessment [48].

In addition, our work demonstrates that interdependency is not only linked with sectors, but also with time. Many business analysts believe the impact of flooding on manufacturing companies is short-lived and that they normally bounce back after the event. We hereby provide contrary evidence that post-disaster, the financial losses for firms could still be significant.

Managing these risks, at the firm level, locally, as well as nationally is therefore important, particularly given the expected increase in flood risk in many parts of China due to climate change. A variety of measures can help to reduce flood risk, including engineering and management solutions. Firms as well as governments should consider these as part of their business operations and planning policy to reduce current risks and avoid the creation of future risks.

There are several limitations to this study. One is that we present an average effect, but firm characteristics differ, which means that the "true" cost for an individual firm might be larger or smaller depending on its size and that of the sector, which we do not examine. In effect, the "true" cost on individual businesses depends on many factors, such as their supply chain; their adaptive capacity, including their capacity to plan for emergency responses; and the size and exogenous factors such 
as the availability of government assistance among others. Another limitation of this study is the resolution of the floods, which is at the city scale. It would be preferable to use the actual extent of floods to improve the precision of the geo-location of affected firms.

In addition, this is only a partial review of flood impacts, as we focus on the manufacturing sector and propagating effects on the broader economy; there would also have been impacts on other sectors as well as households. Further, we are not able to incorporate the costs of capital replacement, reconstruction, and replacement of damaged stocks as our measure of firm output is based on an index of revenue and labor. The inclusion of such estimates is not possible due to a lack of data availability.

Overall, our research demonstrates the scale and distribution (across economic sectors and geographically) of flood risk. Risk analysis that fully quantifies the potential impacts of flooding provides the basis for appraising policy and investment interventions to manage flood risk. Without accurate risk analysis, the resources for flood risk management may be under-provided or miss-allocated. In addition, our research provides specific evidence for firms that may not be fully aware of the extent of their exposure to flood risk, so they may be under-investing in risk management instruments such as insurance. As such, this work calls for a more comprehensive assessment of flooding impacts at the firm level and their propagating macroeconomic effects. This is because firms ultimately bear the business costs of extreme weather events, yet we do not understand how they are affected, nor do we understand how other sectors may be impacted owing to the interconnectivity of the economy. Further work could apply more nuanced IO and CGE models which capture firm and household responses, although the limited availability of data currently prohibits us from conducting such work.

Author Contributions: Conceptualization, X.H., R.P., S.S. and J.W.H.; methodology, X.H., R.P., J.W.H and J.H.; formal analysis, X.H., R.P.; resources, S.S., J.W.H.; data curation, X.H., S.S.; writing-original draft preparation, X.H., R.P.; writing—review and editing, X.H., R.P., S.S., J.W.H. and J.H; visualization, X.H. and R.P.

Funding: This research was funded by the Asian Studies Centre at the University of Oxford and the European Commission ECOCEP Project. The authors, Raghav Pant and Jim W Hall, acknowledge the contribution of the Infrastructure Transitions Research Consortium (ITRC), which is funded by the UK Engineering and Physical Sciences Research Council (EPSRC) under two program grants EP/I01344X/1 and EP/N017064/1. Surminski would like to acknowledge the support from the UK Economic and Social Research Council (ESRC) through the Centre for Climate Change Economics and Policy (CCCEP) [grant number ES/K006576/1] and the Grantham Foundation for the Protection of the Environment. Jiashun Huang acknowledges support from the Swire Educational Trust, the GEMCLIME Project from the European Union's Horizon 2020 Research and Innovation Programme (GA No. 681228) and the ITRC.

Acknowledgments: We thank Jonathan Colmer at the University of Virginia and Valerie Bevan for their comments on the paper.

Conflicts of Interest: The authors declare no conflict of interest. The funders had no role in the design of the study; in the collection, analyses, or interpretation of data; in the writing of the manuscript, or in the decision to publish the results.

\section{Appendix A}

Table A1. Manufacturing sub-sectors included in the analysis.

\begin{tabular}{cc}
\hline Sector & Name \\
\hline $1-5$ & Food products, Beverages, Tobacco products, Textiles, Wearing apparel \\
$6-8$ & Leather and related products, Wood and products, Paper and paper products \\
$9-11$ & Printing and reproduction of records, Coke and refined petroleum, Chemicals \\
$12-14$ & Basic pharmaceuticals, Rubber and plastics, Other non-metallic metals \\
$15-18$ & Basic metals, Fabricated metal products, Computer, Electrical equipment \\
$19-20$ & Machinery, Motor vehicles, trailers and semi-trailers \\
$21-23$ & Other transport equipment, Furniture, Others \\
\hline
\end{tabular}




\section{Appendix B}

Table A2. Hausman test on fixed and random effects models.

\begin{tabular}{|c|c|c|c|c|}
\hline & $\begin{array}{c}\text { Coefficients } \\
(\mathrm{b}) \\
\text { Fixed-effect Model }\end{array}$ & $\begin{array}{c}\text { (B) } \\
\text { Random-effect Model }\end{array}$ & (b-B) & $\operatorname{sqrt}($ diag(V_b-V_B $))$ \\
\hline $\begin{array}{c}\text { Flood } \\
\text { Sector Control }\end{array}$ & $\begin{array}{c}-0.2826193 \\
\text { Yes }\end{array}$ & $\begin{array}{c}-0.6946531 \\
\text { Yes }\end{array}$ & 0.4120337 & 0.0065373 \\
\hline
\end{tabular}

Test: Ho: difference in coefficients not systematic

$$
\begin{gathered}
\text { chi2 }(2)=(\mathrm{b}-\mathrm{B})^{\prime}\left[\left(\mathrm{V} \_\mathrm{b}-\mathrm{V} \_\mathrm{B}\right)^{\wedge}(-1)\right](\mathrm{b}-\mathrm{B}) \\
=3741.76 \\
\text { Prob }>\text { chi } 2=0.0000 \\
\left(\mathrm{~V} \_\mathrm{b}-\mathrm{V} \_\mathrm{B} \text { is not positive definite }\right)
\end{gathered}
$$

\section{References}

1. Natural Disasters 2017. Available online: https:/ / www.emdat.be (accessed on 5 December 2018).

2. Supply Chain Resilience 2011. Available online: https://www.cips.org/Documents/Resources/ KnowledgeSummary / BCISupplyChainResilience2011PublicVersion.pdf (accessed on 5 December 2018).

3. Bulletin of Flood and Drought Disasters in China 2017. Available online: http://www.mwr.gov.cn/sj/tjgb / zgshzhgb /201808/t20180806_1044770.html (accessed on 5 December 2018).

4. Willner, S.; Otto, C.; Levermann, A. Global economic response to river floods. Nat. Clim. Chang. 2018, 8, 594-598. [CrossRef]

5. Li, L. China's manufacturing locus in 2025: With a comparison of "Made-in-China 2025" and "Industry 4.0.". Technol. Forecast. Soc. Chang. 2018, 135, 66-74. [CrossRef]

6. Haraguchi, M.; Lall, U. Flood risks and impacts: A case study of Thailand's floods in 2011 and research questions for supply chain decision making. Int. J. Disaster Risk Reduct. 2015, 14, 256-272. [CrossRef]

7. Hayakawa, K.; Matsuura, T.; Okubo, F. Firm-level impacts of natural disasters on production networks: Evidence from a flood in Thailand. J. Jpn. Int. Econ. 2015, 38, 244-259. [CrossRef]

8. Survey of Business Sentiment on Japanese corporations in Thailand for the 2nd Half of 2011. Available online: https://www.jetro.go.jp/ext_images/thailand/e_survey/pdf/jccspr12eng.pdf (accessed on 5 December 2018).

9. Companies in the A-share and NEEQ Markets that Are Struggling to Fight Floods. Available online: http://www.sohu.com/a/105203868_285227 (accessed on 29 November 2018).

10. China's Manufacturing Gauge Pulled Under by Heavy Flooding. Available online: https://www.ft.com/ content/4dc1c436-40b2-3107-a4e4-766aaed99914 (accessed on 3 December 2018).

11. Merz, B.; Kreibich, H.; Schwarze, R.; Thieken, A. Review article "assessment of economic flood damage". Nat. Hazards Earth Syst. Sci. 2010, 10, 1697-1724. [CrossRef]

12. Kreibich, H.; van den Bergh, J.C.J.M.; Bouwer, L.M.; Bubeck, P.; Ciavola, P.; Green, C.; Hallegatte, S.; Logar, I.; Meyer, V.; Schwarze, R.; et al. Costing natural hazards. Nat. Clim. Chang. 2014, 4, 303-306. [CrossRef]

13. Kousky, C. Informing Climate Adaptation: A Review of the Economic Costs of Natural Disasters, Their Determinants, and Risk Reduction Options. Energy Econ. 2014, 46, 576-592. [CrossRef]

14. Meyer, V.; Becker, N.; Markantonis, V.; Schwarze, R.; Van Den Bergh, J.; Bouwer, L.; Bubeck, P.; Ciavola, P.; Genovese, E.; Green, C.; et al. Review article: Assessing the costs of natural hazards-state of the art and knowledge gaps. Nat. Hazards Earth Syst. Sci. 2013, 13, 1351-1373. [CrossRef]

15. Skidmore, M.; Toya, H. Do natural disasters promote long-run growth? Econ. Inq. 2002, 40, 664-687. [CrossRef]

16. Schumacher, I.; Strobl, E. Economic development and losses due to natural disasters: The role of hazard exposure. Ecol. Econ. 2011, 72, 97-105. [CrossRef] 
17. Parker, M. The Impact of Disasters on Inflation. Econ. Disasters Clim. Chang. 2018, 2, 21-48. [CrossRef]

18. Mohan, P.; Strobl, E. The short-term economic impact of tropical Cyclone Pam: An analysis using VIIRS nightlight satellite imagery. Int. J. Remote Sens. 2017, 38, 5992-6006. [CrossRef]

19. Molinari, D.; Menoni, S.; Aronica, G.; Ballio, F.; Berni, N.; Pandolfo, C.; Stelluti, M.; Minucci, G. Ex post damage assessment: An Italian experience. Nat. Hazards Earth Syst. Sci. 2014, 14, 901-916. [CrossRef]

20. Ayyub, B.; Braileanu, H.; Qureshi, N. Prediction and Impact of Sea Level Rise on Properties and Infrastructure of Washington, DC. Risk Anal. 2012, 32, 1901-1918. [CrossRef]

21. Raschky, P. Institutions and the losses from natural disasters. Nat. Hazards Earth Syst. Sci. 2008, 8, 627-634. [CrossRef]

22. Rajapaksa, D.; Wilson, C.; Managi, S.; Hoang, V.; Lee, B. Flood Risk Information, Actual Floods and Property Values: A Quasi-Experimental Analysis. Econ. Rec. 2016, 92, 52-67. [CrossRef]

23. Zhang, L. Flood hazards impact on neighborhood house prices: A spatial quantile regression analysis. Reg. Sci. Urban Econ. 2016, 60, 12-19. [CrossRef]

24. Zou, H.; Adams, M.B.; Buckle, M.J. Corporate Risks and Property Insurance: Evidence From the People's Republic of China. J. Risk Insur. 2003, 70, 289-314. [CrossRef]

25. Kreibich, H.; Müller, M.; Thieken, A.; Merz, B. Flood precaution of companies and their ability to cope with the flood in August 2002 in Saxony, Germany. Water Resour. Res. 2007, 43. [CrossRef]

26. Tierney, K.J. Businesses and Disasters: Vulnerability, Impacts, and Recovery. In Handbook of Disaster Research. Handbooks of Sociology and Social Research; Springer: New York, NY, USA, 2007; pp. 275-296.

27. Davlasheridze, M.; Geylani, P. Small Business vulnerability to floods and the effects of disaster loans. Small Bus. Econ. 2017, 49, 865-888. [CrossRef]

28. Leiter, A.; Oberhofer, H.; Raschky, P. Creative Disasters? Flooding Effects on Capital, Labour and Productivity Within European Firms. Environ. Resour. Econ. 2009, 43, 333-350. [CrossRef]

29. Noth, F.; Rehbein, O. Badly hurt? Natural disasters and direct firm effects. Financ. Res. Lett. 2018, 1-5. [CrossRef]

30. Coelli, F.; Manasse, P. The Impact of Floods on Firms' Performance. Available online: http:/ /dx.doi.org/10. 2139/ssrn.2440712 (accessed on 1 April 2019).

31. Rose, A.; Liao, S. Modeling regional economic resilience to disasters: A computable general equilibrium analysis of water service disruptions. J. Reg. Sci. 2005, 45, 75-112. [CrossRef]

32. Okuyama, Y.; Santos, J. Disaster Impact and Input-Output Analysis. Econ. Syst. Res. 2014, $26,1-12$. [CrossRef]

33. Carrera, L.; Standardi, G.; Bosello, F.; Mysiak, J. Assessing direct and indirect economic impacts of a flood event through the integration of spatial and computable general equilibrium modelling. Environ. Model. Softw. 2015, 63, 109-122. [CrossRef]

34. Li, J.; Crawford-Brown, D.; Syddall, M.; Guan, D. Modeling imbalanced economic recovery following a natural disaster using input-output analysis. Risk Anal. 2013, 33, 1908-1923. [CrossRef] [PubMed]

35. Koks, E.; Thissen, M. A Multiregional Impact Assessment Model for disaster analysis. Econ. Syst. Res. 2016, 28, 429-449. [CrossRef]

36. Mackenzie, C.A.; Santos, J.R.; Barker, K. Measuring changes in international production from a disruption: Case study of the Japanese earthquake and tsunami. Intern. J. Prod. Econ. 2012, 138, 293-302. [CrossRef]

37. Koks, E.; Bočkarjova, M.; de Moel, H.; Aerts, J. Integrated direct and indirect flood risk modeling: Development and sensitivity analysis. Risk Anal. 2015, 35, 882-900. [CrossRef]

38. Albala-Bertrand, J. Disasters and the Networked Economy; Routledge: London, UK, 2013.

39. Steenge, A.; Bočkarjova, M. Thinking about imbalances in post-catastrophe economies: An input-output based proposition. Econ. Syst. Res. 2007, 19, 205-223. [CrossRef]

40. Hallegatte, S. An adaptive regional input-output model and its application to the assessment of the economic cost of Katrina. Risk Anal. 2008, 28, 779-799. [CrossRef] [PubMed]

41. Hallegatte, S. Modeling the role of inventories and heterogeneity in the assessment of the economic costs of natural disasters. Risk Anal. 2014, 34, 152-167. [CrossRef] [PubMed]

42. Orbis. Available online: https://www.bvdinfo.com/en-gb/our-products/data (accessed on 1 December 2014).

43. Global Active Archive of Large Flood Events. Available online: http://floodobservatory.colorado.edu/ Archives/index.html (accessed on 22 December 2016). 
44. Stock, J.; Watson, M. Introduction to Econometrics; Prentice Hall: New York, NY, USA, 2003.

45. Haltiwanger, J.; Lane, J.; Spletzer, J. Productivity Differences Across Employers: The Roles of Employer Size, Age, and Human Capital. Am. Econ. Rev. 1999, 89, 94-98. [CrossRef]

46. Oosterhaven, J. On the Plausibility of the Supply-Driven Input-Output Model. J. Reg. Sci. 1988, $28,203-217$. [CrossRef]

47. Leontief, W. Input-Output Economics; Oxford University Press: New York, NY, USA, 1988.

48. Bulletin of Flood and Drought Disasters in China 2010. Available online: http://www.mwr.gov.cn/sj/tjgb/ zgshzhgb/201612/t20161222_776088.html (accessed on 5 December 2018).

(C) 2019 by the authors. Licensee MDPI, Basel, Switzerland. This article is an open access article distributed under the terms and conditions of the Creative Commons Attribution (CC BY) license (http://creativecommons.org/licenses/by/4.0/). 